\title{
The effects of incremental continuous positive airway pressure on arterial oxygenation and pulmonary shunt during one-lung ventilation
}

\author{
Yeon Dong Kim ${ }^{1}$, Seonghoon $\mathrm{Ko}^{1}$, Deokkyu Kim ${ }^{1}$, Hyungsun $\mathrm{Lim}^{1}$, Ji Hye Lee ${ }^{1}$, and Min Ho Kim² \\ Departments of ${ }^{1}$ Anesthesiology and Pain Medicine, ${ }^{2}$ Thorasic and Cardiovascular Surgery, Chonbuk National University Medical \\ School, Jeonju, Korea
}

Background: Although one lung ventilation (OLV) is frequently used for facilitating thoracic surgical procedures, arterial hypoxemia can occur while using one lung anesthesia. Continuous positive airway pressure (CPAP) in 5 or $10 \mathrm{cmH}_{2} \mathrm{O}$ to the non-ventilating lung is commonly recommended to prevent hypoxemia. We evaluated the effects of incremental CPAP to the non-ventilating lung on arterial oxygenation and pulmonary shunt without obstruction of the surgical field during OLV.

Methods: Twenty patients that were scheduled for one lung anesthesia were included in this study. Systemic and pulmonary hemodynamic data and blood gas analysis was recorded every fifteen minutes according to the patient's positions and CPAP levels. CPAP was applied from $0 \mathrm{cmH}_{2} \mathrm{O}$ by $3 \mathrm{cmH}_{2} \mathrm{O}$ increments until a surgeon notifies that the surgical field was obstructed by the expanded lung. Following that, pulmonary shunt fraction $\left(\mathrm{Q}_{\mathrm{S}} / \mathrm{Q}_{\mathrm{T}}\right)$ was calculated. Results: There were no significant differences of $Q_{S} / Q_{T}$ between supine and lateral positions with two lung ventilation (TLV). OLV significantly decreased arterial oxygen partial pressure $\left(\mathrm{PaO}_{2}\right)$ and increased $\mathrm{Q}_{\mathrm{S}} / \mathrm{Q}_{\mathrm{T}}$ compared to TLV. $\mathrm{PaO}_{2}$ and $\mathrm{Q}_{\mathrm{S}} / \mathrm{Q}_{\mathrm{T}}$ significantly improved at 6 and $9 \mathrm{cmH}_{2} \mathrm{O}$ of CPAP compared to $0 \mathrm{cmH}_{2} \mathrm{O}$. However, there were no significant differences of $\mathrm{PaO}_{2}$ and $\mathrm{Q}_{\mathrm{S}} / \mathrm{Q}_{\mathrm{T}}$ between 6 and $9 \mathrm{cmH}_{2} \mathrm{O}$ CPAP. In 18 patients $(90 \%)$, surgical fields were obstructed at $9 \mathrm{cmH}_{2} \mathrm{O}$ CPAP.

Conclusions: This study suggests that $6 \mathrm{cmH}_{2} \mathrm{O}$ CPAP effectively improved arterial oxygenation without interference of the surgical field during OLV when CPAP was applied from $0 \mathrm{cmH}_{2} \mathrm{O}$ in $3 \mathrm{cmH}_{2} \mathrm{O}$ increments. (Korean J Anesthesiol 2012; 62: 256-259)

Key Words: Continuous positive airway pressure, One lung ventilation, Oxygenation, Surgical field.

Received: June 7, 2011. Revised: 1st, July 25, 2011; 2nd, August 19, 2011. Accepted: September 5, 2011.

Corresponding author: Seonghoon Ko, M.D., Ph.D., Department of Anesthesiology and Pain Medicine, Chonbuk National University Medical School, 634-18, Geumam-dong, Deokjin-gu, Jeonju 561-712, Korea. Tel: 82-63-250-1241, Fax: 82-63-250-1240, E-mail: shko@jbnu.ac.kr (c) This is an open-access article distributed under the terms of the Creative Commons Attribution Non-Commercial License (http:// creativecommons.org/licenses/by-nc/3.0/), which permits unrestricted non-commercial use, distribution, and reproduction in any medium, provided the original work is properly cited. 


\section{Introduction}

One lung ventilation (OLV) during thoracic surgery leads to a good surgical field by making the lung collapse, which makes it easy to perform the operation. OLV is used to protect normal lungs from inflammatory tissue, abscess, or hemorrhage by separating normal lungs from the affected lung [1]. As minimal invasive surgeries such as video-assisted thoracic surgery have increased, the requirement for OLV has also been increasing.

Despite its advantages, OLV has major complications such as ventilation-perfusion mismatch and intrapulmonary shunt that can cause hypoxemia [2]. A number of methods to prevent hypoxemia have been introduced. These include applying continuous positive airway pressure (CPAP) to the non-ventilated lung, and positive end-expiratory pressure (PEEP) to the ventilated lung or both. However, CPAP inflates the collapsed lung and this can interfere with surgery. Although many previous studies [3-5] demonstrated the effects of CPAP on arterial oxygenation, the effects of CPAP on the surgical field were not evaluated.

In this study, we investigated the effects of incremental CPAP to the non-ventilating lung on arterial oxygenation and pulmonary shunt, as well as determining the level at which CPAP can interfere with the surgical field.

\section{Materials and Methods}

Twenty patients (American Society of Anesthesiologists 1 to 3) scheduled to have elective thoracic surgery requiring OLV under general anesthesia, were included this study. Exclusion criteria included lung resection history, obstructive and restrictive lung diseases, and severe cardiovascular disease. The study was conducted after approval from the institutional ethics committee as well as receiving informed consent from all study participants.

No pre-anesthetic medication was administrated. After arriving at the operating room, the patients were monitored by ECG, NIBP, and pulse oxymetry. After modified Allen's test, a 20 gauge arterial catheter was inserted into the radial artery to measure direct blood pressure and to sample the arterial blood for blood gas analysis. Anesthesia was induced by thiopental sodium $4-5 \mathrm{mg} / \mathrm{kg}$, and vecuronium $0.10-0.15 \mathrm{mg} / \mathrm{kg}$ was injected to facilitate tracheal intubation. After induction of anesthesia, 37 Fr. of double lumen endotracheal tube (Bronchocath $^{\circledR}$, Mallinckrodt, Athlone, Ireland) was intubated for male patients, and 35 Fr. for female patients. Position of the tube was checked by auscultation, and confirmed by flexible fiberoptic bronchoscopy (BRO-Y $\mathrm{Y}_{3} \mathrm{~S}, \mathrm{Fujinon}$, Japan). Anesthesia was maintained by fixed 1.5 minimum alveolar concentration (MAC) of sevoflurane and $1-5 \mathrm{ng} / \mathrm{ml}$ effect-site concentrations of remifentanil was co-administered using a target controlled infusion (TCI) pump (Orchestra ${ }^{\circledR}$, Fresenius Vial, France).

During the operation, fresh gas flow rate and inspired fraction of oxygen $\left(\mathrm{FiO}_{2}\right)$ were $5 \mathrm{~L} / \mathrm{min}$ and 1.0, respectively. Minute ventilation was controlled by $10 \mathrm{ml} / \mathrm{kg}$ of tidal volume (TV), and the respiratory rate was adjusted to $35-38 \mathrm{mmHg}$ of end-tidal $\mathrm{CO}_{2}$ pressure. Fresh gas flow rate, $\mathrm{FiO}_{2}$, and TV were maintained in the study period during OLV. Pulmonary artery catheter (Balloon thermodilution catheter, 7Fr. ARROW, USA) was inserted in to the right internal jugular vein. A portable chest X-ray was taken to confirm the accurate catheter position. Cardiac output was measured by the thermodilution method, and arterial and mixed venous bloods were sampled for gas analysis. After changing the patient's position from supine to lateral, the location of double lumen endotracheal tube was rechecked by flexible fiberoptic bronchoscopy.

Systolic, diastolic, and mean blood pressures (BP), heart rate (HR), systemic vascular resistance (SVR), central venous pressure (CVP), cardiac output (CO), arterial blood gas analysis (ABGA), and mixed venous blood gas analysis (VBGA) were recorded at: 1) supine position with $T L V, 2$ ) lateral position before opening chest wall with TLV, 3) lateral position after opening chest wall with TLV, 4) OLV without CPAP, and 5) OLV with CPAP by increment of $3 \mathrm{cmH}_{2} \mathrm{O}$ using the CPAP device (Bronchocath ${ }^{\circledR}$ CPAP system, Mallinckrodt, USA). For an accurate measurement of CPAP, U-shaped water columns were connected to the CPAP device and the pressure difference between the two columns was measured. Hemodynamic parameters and blood gas analysis were measured 15 minutes after changing position and applying different levels of CPAP. CPAP application was ceased when a surgeon mentioned that the expanded lung interfered with the surgical field. The entire operation was conducted by a single surgeon.

Cardiac output was measured three times by the thermodilution method and averaged at every period. Intrapulmonary shunt fraction $\left(\mathrm{Q}_{\mathrm{S}} / \mathrm{Q}_{\mathrm{T}}\right)$ was calculated by the following formula: $\mathrm{Q}_{\mathrm{S}} / \mathrm{Q}_{\mathrm{T}}=\left(\left[\mathrm{P}_{\mathrm{A}} \mathrm{O}_{2}-\mathrm{PaO}_{2}\right] \times 0.003\right) /\left(3.5+\left[\mathrm{P}_{\mathrm{A}} \mathrm{O}_{2}-\mathrm{PaO}_{2}\right] \times 0.003\right)$ [6]. This formula was used according to Shapiro's theory that under circumstance $\mathrm{FiO}_{2}$ more than 0.3, pulmonary end capillary oxygen content can be regarded as $100 \%$ [7]. Data were expressed by mean \pm standard deviation. Repeat measured ANOVA was used for statistical analysis and Holm-Sidak test as post-hoc test was performed. If the $P$ value $<0.05$, the result was considered statistically significant.

\section{Results}

Patient's characteristics are shown in Table 1. Of the 20 patients, CPAP application was ceased for 18 patients at $9 \mathrm{cmH}_{2} \mathrm{O}$ and for 2 patients at $12 \mathrm{cmH}_{2} \mathrm{O}$ when the surgical field was 
interfered. Hemodynamic data is presented in Table 2. Cardiac output significantly increased when the chest wall was opened. Arterial oxygen partial pressure $\left(\mathrm{PaO}_{2}\right)$ was decreased from $452 \pm 38 \mathrm{mmHg}$ to $251 \pm 136 \mathrm{mmHg}$ by OLV and significantly

Table 1. Patient Characteristics in this Study

\begin{tabular}{llc}
\hline Gender (M/F) & $16 / 4$ \\
Age $(\mathrm{yr})$ & $59.1 \pm 10.2$ \\
Height $(\mathrm{cm})$ & $165.1 \pm 4.3$ \\
Weight $(\mathrm{kg})$ & $60.5 \pm 11.1$ \\
Anesthesia time (min) & & $233 \pm 37$ \\
Type of surgery & Pneumonectomy & Rt (6), Lt (4) \\
& Lobectomy & Rt upper lobe (5) \\
& & Lt upper lobe (5) \\
\hline
\end{tabular}

increased at a pressure of 6 and $9 \mathrm{cmH}_{2} \mathrm{O}$ CPAP to $383 \pm 103$ and $375 \pm 131$, respectively. However, $\mathrm{PaO}_{2}$ was not significantly different between 6 and $9 \mathrm{cmH}_{2} \mathrm{O}$ CPAP (Fig. 1).

After the chest wall was opened, $\mathrm{Q}_{\mathrm{S}} / \mathrm{Q}_{\mathrm{T}}$ increased from 15 \pm 3.1 to $26 \pm 6.6$ by OLV . At $6 \mathrm{cmH}_{2} \mathrm{O} \mathrm{CPAP}, \mathrm{Q}_{\mathrm{S}} / \mathrm{Q}_{\mathrm{T}}$ was $19 \pm 5.5$ which was not significantly different from TLV (Fig. 2). Four patients showed less than $100 \mathrm{mmHg}$ of $\mathrm{PaO}_{2}$ at the time OLV start. Of them, 3 patients in $3 \mathrm{cmH}_{2} \mathrm{O}$ and 1 patient in $6 \mathrm{cmH}_{2} \mathrm{O}$ CPAP showed $\mathrm{PaO}_{2}$ improvement of more than $100 \mathrm{mmHg}$.

\section{Discussion}

Because $\mathrm{PaO}_{2}$ can decrease by increased intrapulmonary shunt fraction during OLV [8], an important aspect of anesthetic

Table 2. Hemodynamic Data Collected in this Study

\begin{tabular}{lcccccccc}
\hline Supine & Lateral & $\begin{array}{c}\text { Chest open } \\
\text { (TLV) }\end{array}$ & $\begin{array}{c}\text { OLV } \\
\text { (CPAP 0) }\end{array}$ & $\begin{array}{c}\text { OLV } \\
\text { (CPAP 3) }\end{array}$ & $\begin{array}{c}\text { OLV } \\
\text { (CPAP 6) }\end{array}$ & $\begin{array}{c}\text { OLV } \\
\text { (CPAP 9) }\end{array}$ & $\begin{array}{c}\text { TLV } \\
\text { (Post OLV) }\end{array}$ \\
\hline MAP & $64.3 \pm 5.3$ & $66.2 \pm 9.8$ & $77.8 \pm 10.5^{*}$ & $66.8 \pm 8.2$ & $70.5 \pm 10.1$ & $72.7 \pm 10.1^{*}$ & $74.7 \pm 5.8^{*}$ & $69.6 \pm 9.7$ \\
HR & $64.4 \pm 9.1$ & $60.0 \pm 9.3$ & $68.6 \pm 8.6$ & $72.5 \pm 8.4^{*}$ & $71.5 \pm 7.4$ & $71.1 \pm 7.1$ & $75.7 \pm 5.6^{*}$ & $68.9 \pm 6.2$ \\
MPAP & $19.4 \pm 4.8$ & $18.8 \pm 6.9$ & $19.8 \pm 5.8$ & $18.6 \pm 3.0$ & $20.7 \pm 2.1$ & $20.8 \pm 3.2$ & $22.8 \pm 4.3$ & $21.8 \pm 2.5$ \\
CVP & $8.8 \pm 3.0$ & $8.7 \pm 2.9$ & $8.1 \pm 1.9$ & $8.0 \pm 2.0$ & $8.6 \pm 1.7$ & $8.9 \pm 1.2$ & $8.5 \pm 1.5$ & $8.6 \pm 1.4$ \\
CO & $3.34 \pm 0.7$ & $3.74 \pm 0.8$ & $4.52 \pm 0.6^{*}$ & $4.51 \pm 0.4^{*}$ & $4.84 \pm 0.6^{*}$ & $4.93 \pm 0.8^{*}$ & $5.05 \pm 1.3^{*}$ & $5.30 \pm 1.2^{*}$ \\
SVR & $1,387.9 \pm 299.3$ & $1,333.1 \pm 308.8$ & $1,308.5 \pm 175.8$ & $1,083.6 \pm 167.3$ & $1,027.8 \pm 251.1$ & $1,080.1 \pm 336.4$ & $1,043.4 \pm 201.6$ & $1,026.6 \pm 344.6$ \\
\hline
\end{tabular}

Values are expressed as mean \pm SD. MAP: mean arterial pressure (mmHg), HR: heart rate (beat/min), MPAP: mean pulmonary artery pressure (mmHg), CVP: central venous pressure (mmHg), CO: cardiac output, SVR: systemic vascular resistance (dyne $\cdot \mathrm{sec} / \mathrm{cm}^{5}$ ), TLV: two lung ventilation, OLV: one lung ventilation, CPAP: continuous positive airway pressure. *Significantly different $(\mathrm{P}<0.05)$ from supine position with two lung ventilation.

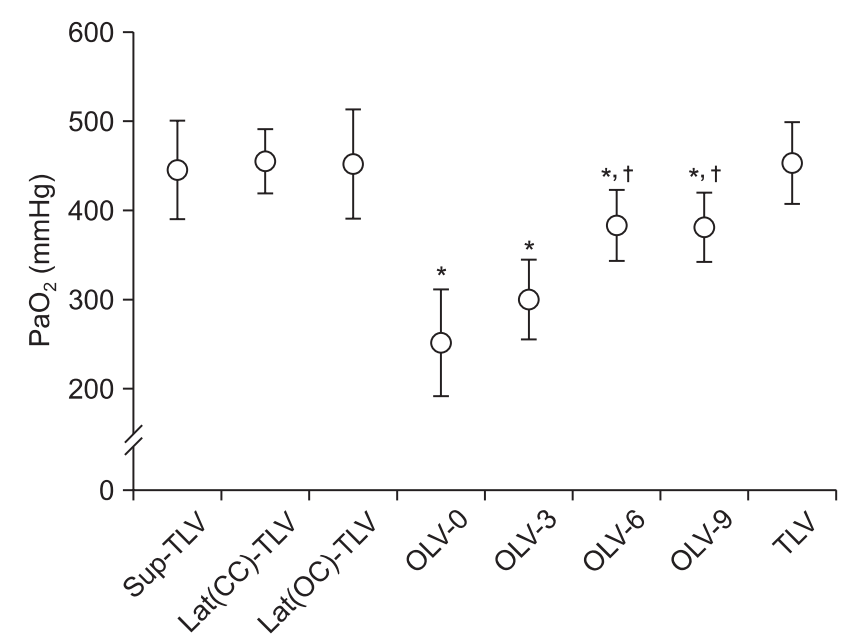

Fig. 1. Arterial oxygen partial pressure $\left(\mathrm{PaO}_{2}\right)$ decreased by OLV and significantly increased at the pressure of 6 and $9 \mathrm{cmH}_{2} \mathrm{O}$ CPAP. All data are expressed as mean \pm S.D. Sup-TLV: supine position with two lung ventilation, Lat(CC)-TLV: lateral position with two lung ventilation before chest cavity open, Lat(OC)-TLV: lateral position with two lung ventilation after chest cavity open, OLV-0, 3, 6 ,9: one lung ventilation with CPAP $0,3,6,9 \mathrm{cmH}_{2} \mathrm{O}$, TLV: two lung ventilation after stop CPAP. *Significantly different $(\mathrm{P}<0.05)$ from supine position with two lung ventilation (Sup-TLV). ${ }^{\dagger}$ Significantly different $(\mathrm{P}<0.05)$ from one lung ventilation without CPAP $(\mathrm{OLV}-0)$.

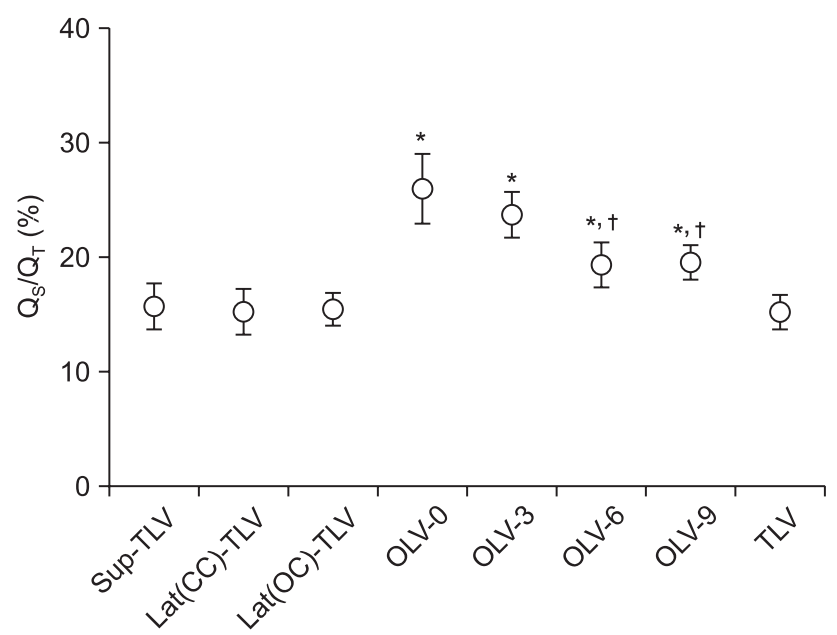

Fig. 2. Pulmonary shunt fraction $\left(\mathrm{Q}_{\mathrm{S}} / \mathrm{Q}_{\mathrm{T}}\right)$ increased by OLV. All data are expressed as mean \pm S.D. Sup-TLV: supine position with two lung ventilation, Lat(CC)-TLV: lateral position with two lung ventilation before chest cavity open, Lat(OC)-TLV: lateral position with two lung ventilation after chest cavity open, $\mathrm{OLV}-0,3,6,9$ : one lung ventilation with CPAP 0, 3, 6, $9 \mathrm{cmH}_{2} \mathrm{O}$, TLV: two lung ventilation after stop CPAP. * Significantly different $(\mathrm{P}<0.05)$ from supine position with two lung ventilation (Sup-TLV). ${ }^{\dagger}$ Significantly different $(\mathrm{P}<0.05)$ from one lung ventilation without CPAP (OLV-0). 
management during OLV is to prevent this mechanism. The anesthetic methods to increase $\mathrm{PaO}_{2}$ include using high $\mathrm{FiO}_{2}$ [8], application of positive end expiratory pressure (PEEP) to the dependent lung [9] and/or CPAP to the nondependent lung [10], intermittent TLV, and temporary ligation of the pulmonary artery [11]. Although CPAP is commonly recommended to prevent hypoxemia to the non-ventilating lung because of its simplicity and effect [12], high levels of CPAP to the operating lung can interfere with the surgical field. We attempted to evaluate the effects of incremental CPAP on $\mathrm{PaO}_{2}$ and $\mathrm{Q}_{\mathrm{S}} / \mathrm{Q}_{\mathrm{T}}$ during OLV and determine the level of CPAP that could interfere with the surgical field. We found that $6 \mathrm{cmH}_{2} \mathrm{O}$ CPAP effectively improved arterial oxygenation without the interference of the surgical field during OLV.

In previous studies [3-5,13], CPAP application to the nonventilating lung increased $\mathrm{PaO}_{2}$ and decreased $\mathrm{Q}_{\mathrm{S}} / \mathrm{Q}_{\mathrm{T}}$. However, these studies did not consider ensuring the surgical field, which is the main purpose of OLV. In our results, $6 \mathrm{cmH}_{2} \mathrm{O}$ CPAP compared with $9 \mathrm{cmH}_{2} \mathrm{O}$ did not interfere with the surgical field in most patients without any significant differences between $\mathrm{PaO}_{2}$ and $\mathrm{Q}_{\mathrm{S}} / \mathrm{Q}_{\mathrm{T}}$. A total of $3 \mathrm{cmH}_{2} \mathrm{O}$ CPAP did not show any effects on $\mathrm{PaO}_{2}$ and $\mathrm{Q}_{\mathrm{S}} / \mathrm{Q}_{\mathrm{T}}$, although the surgical field was not interfered with by the expanded lung in all patients tested.

Theoretically, a high pressure of CPAP on the non-ventilated lung moves more blood flow to the ventilated lung so that it seems to increase $\mathrm{PaO}_{2}$ to a greater exchange by pulmonary gas exchange. Alfery et al. [13] reported blood flow to the nonventilated lung considerably decreased after adding $15 \mathrm{cmH}_{2} \mathrm{O}$ of CPAP, but $\mathrm{PaO}_{2}$ and shunt decreasing rate was similar to that of $10 \mathrm{cmH}_{2} \mathrm{O}$. However, an expanded lung by high pressure of CPAP can interfere with the surgical field. This goes against the main purpose of OLV. Although we did not apply CPAP to 10 $\mathrm{cmH}_{2} \mathrm{O}, 6 \mathrm{cmH}_{2} \mathrm{O}$ CPAP was significantly effective in preventing hypoxemia and securing the surgical field compared with 9 $\mathrm{cmH}_{2} \mathrm{O}$ CPAP.

We found that 4 patients (20\%) showed less than $100 \mathrm{mmHg}$ of $\mathrm{PaO}_{2}$ although mean $\mathrm{PaO}_{2}$ was $251 \pm 136$ mmHg during OLV. A total of 3 and 1 patient with 3 and $6 \mathrm{cmH}_{2} \mathrm{O}$ of CPAP improved $\mathrm{PaO}_{2}$ more than $100 \mathrm{mmHg}$, respectively. In 18 patients (90\%), $9 \mathrm{cmH}_{2} \mathrm{O}$ CPAP interfered with the surgical field. Therefore, our study recommends using gradual increments of CPAP from low pressure at the beginning of CPAP application to improve oxygenation and secure the surgical field rather than fixed high pressure CPAP.

There were some limitations in this study. First, the lung was ventilated with $\mathrm{FiO}_{2} 1.0$ and CPAP increased by $3 \mathrm{cmH}_{2} \mathrm{O}$. If the lung was ventilated with less than $\mathrm{FiO}_{2} 1.0$ or CPAP increased by 1 or $2 \mathrm{cmH}_{2} \mathrm{O}$, the best pressure of CPAP could be different with what we found. Second, because there were no patients with significant hypoxemia during OLV in this study, there were some limitations in applying CPAP with our results to the patients with severe hypoxemia. Third, interference with the surgical field was a single thoracic surgeon's subjective decision. The decision could be affected by several factors, including the techniques used by the surgeon as well as the range and site of the lung resection. In conclusion, $6 \mathrm{cmH}_{2} \mathrm{O}$ CPAP effectively improved arterial oxygenation without interference of the surgical field during OLV when CPAP was applied from $0 \mathrm{cmH}_{2} \mathrm{O}$ in 3 $\mathrm{cmH}_{2} \mathrm{O}$ increments.

\section{References}

1. Benumof JL. One-lung ventilation and hypoxic pulmonary vasoconstriction: implications for anesthetic management. Anesth Analg 1985; 64: 821-33.

2. Han JI. One lung anesthesia. Korean J Anesthesiol 2005; 48: 449-58.

3. Capan LM, Turndorf H, Patel C, Ramanathan S, Acinapura A, Chalon J. Optimization of arterial oxygenation during one-lung anesthesia. Anesth Analg 1980; 59: 847-51.

4. Cohen E, Eisenkraft JB, Thys DM, Kirschner PA, Kaplan JA. Oxygenation and hemodynamic changes during one-lung ventilation: effects of CPAP10, PEEP10, and CPAP10/PEEP10. J Cardiothorac Anesth 1988; 2: 34-40.

5. Oh YS, Park NH, Kang H. Improving arterial oxygenation with continuous positive airway pressure to the nonventilated lung during one lung ventilation. Korean J Anesthesiol 1993; 26: 93-8.

6. Hess D, Kacmarek RM, Essentials of mechanical ventilation. New York, McGraw-Hill. 1996, pp 156-7.

7. Shapiro BA, Peruzzi WT, Templin R. Clinical application of blood gases. 5th ed. Chicago, Mosby year book. 1994, pp 85-101.

8. Benumof JL. Anesthesia for thoracic surgery. 2nd ed. Philadelphia, WB Saunders. 1995, pp 406-31.

9. Cohen E, Eisenkraft JB. Positive end-expiratory pressure during one-lung ventilation improves oxygenation in patients with low arterial oxygen tensions. J Cardiothorac Vasc Anesth 1996; 10: 57882.

10. Kim YC, Kim KS, Kang WJ, Shin OY, Kwon MI. The arterial oxygenation effects of CPAP to the nonventilated lung during one lung ventilation. Korean J Anesthesiol 1994; 27: 1155-63.

11. Slinger PD, Campos JH. Anesthesia for thoracic surgery. In: Miller's anesthesia. 7th ed. Edited by Miller RD: Philadelphia, Churchill Livingstone Elsevier. 2010, pp 1852-3.

12. Fujiwara M, Abe K, Mashimo T. The effect of positive end-expiratory pressure and continuous positive airway pressure on the oxygenation and shunt fraction during one-lung ventilation with propofol anesthesia. J Clin Anesth 2001; 13: 473-7.

13. Alfery DD, Benumof JL, Trousdale FR. Improving oxygenation during one-lung ventilation in dogs: the effects of positive endexpiratory pressure and blood flow restriction to the nonventilated lung. Anesthesiology 1981; 55: 381-5. 